\title{
IDENTIFICAÇÃo DE TEOREMAS EM AÇÃo NO ENSINO DE AsTroNOMIA NOS ANOS INICIAIS
}

\author{
IDENTIFICATION OF THEOREMS IN ACTION IN ASTRONOMY TEACHING IN THE EARLY \\ YEARS
}

IDENTIFICACIÓN DE TEOREMAS EN ACCIÓN EN LA ENSEÑANZA DE ASTRONOMÍA EN LOS PRIMEROS AÑOS

\section{Mayara Hilgert Pacheco \\ iD 9}

Licenciada em Física (UEM)

Discente de bacharelado em Física (UEM)

mayarahilgert@live.com

\section{Marli Schmitt Zanella iD 9}

Doutorado em Educação para a

Ciência e a Matemática

Docente na Universidade Estadual

de Maringá (UEM)

Docente no Programa de Pósgraduação em Rede para o Ensino das Ciências Ambientais (PROFCIAMB)

marlischmitt@gmail.com

\begin{abstract}
Resumo
Esta pesquisa, de caráter qualitativo, tem como objetivo identificar teoremas em ação mobilizados por uma turma de estudantes do quinto ano do Ensino Fundamental ao resolverem situações de Astronomia. Para tanto, foi elaborada uma sequência didática, com base nos conteúdos sugeridos pela Base Nacional Comum Curricular para o Ensino Fundamental, especificamente para as turmas de $1^{\circ}$ a $5^{\circ}$, que contemplou uma abordagem conceitual sobre o Sol, a Lua e suas fases e o Sistema Solar. Os dados foram coletados por meio de gravações de áudio, debates, produção escrita dos estudantes e entrevistas, os quais foram analisados a partir do referencial da Teoria dos Campos Conceituais (TCC). Como resultados identificamos sete teoremas em ação. Os resultados mostraram a TCC como ferramenta para compreensão do processo de conceitualização dos estudantes por parte dos professores e a identificação da origem de teoremas em ação falsos.
\end{abstract}

Palavras-chave: Teoremas-em-ação. Ensino de Astronomia. Sol.

Recebido em: 16 de junho de 2021. Aprovado em: 21 de agosto de 2021.

Como citar esse artigo (ABNT):

PACHECO, Mayara Hilgert; ZANELLA, Marli Schmitt. Identificação de Teoremas em Ação no ensino de Astronomia nos anos iniciais. Revista Prática Docente, v. 6, n. 2, e071, 2021. http://doi.org/10.23926/RPD.2021.v6.n2.e071.id1230 


\section{Abstract}

This qualitative research aims to identify theorems-in-action are mobilized by a group of students in the fifth year of elementary school when solving Astronomy situations. To this end, a didactic sequence was elaborated, based on the contents suggested by the Common National Curricular Base for Elementary Education, specifically for classes from $1^{\circ}$ to $5^{\circ}$, which included a conceptual approach on the Sun, the Moon, and its phases and the Solar System. The data were collected through audio recordings, debates, students' written production, and interviews, which were analyzed using the Theory of Conceptual Fields (TCC) framework. As a result, we identified seven theorems-in-action, of which five were classified as false and two as true. The results showed CBT as a tool for understanding the students' conceptualization process by teachers and identifying the origin of false theorems-in-action.

Keywords: Theorems-in-Action. Astronomy Education. Sun.

\section{Resumen}

Resumen: Esta investigación cualitativa tiene como objetivo identificar teoremas en acción son movilizados por un grupo de estudiantes de quinto año de primaria al resolver situaciones de Astronomía. Para ello, se elaboró una secuencia didáctica, a partir de los contenidos sugeridos por la Base Curricular Nacional Común de Educación Primaria, específicamente para las clases de $1^{\circ}$ a $5^{\circ}$, que incluyó un abordaje conceptual sobre el Sol, la Luna y sus fases. y el Sistema Solar. Los datos fueron recolectados a través de grabaciones de audio, debates, producción escrita de los estudiantes y entrevistas, los cuales fueron analizados utilizando el marco de la Teoría de Campos Conceptuales (TCC). Como resultado, identificamos siete teoremas en acción, de los cuales cinco se clasificaron como falsos y dos como verdaderos. Los resultados mostraron la TCC como una herramienta para comprender el proceso de conceptualización de los estudiantes por parte de los profesores e identificar el origen de los falsos teoremas en acción.

Palabras clave: Teoremas en acción. Educación astronómica. Sol. 


\section{INTRODUÇÃO}

A Astronomia é a mais antiga das ciências. Segundo Caniato (1993), há registros históricos que remetem a atividades astronômicas ligadas a povos da antiguidade chinesa, babilônica e egípcia, isto é, desde o princípio o homem olhou para o céu noturno em busca de respostas para suas indagações e explicações para os "humores" da natureza. Ainda hoje, a Astronomia é objeto de fascínio e curiosidade. Por isso, para o ensino, a Astronomia possui um papel motivador. Quando o professor aborda temas astronômicos, imediatamente, os alunos se sentem animados, engajados e direcionam uma série de perguntas e teorias sobre exploração espacial, origem do Universo, vida extraterreste, entre outros tópicos.

Nesse cenário, a Astronomia oportuniza ao professor uma abordagem interdisciplinar e essa interdisciplinaridade, segundo Langhi (2016), promove a compreensão de que os saberes científicos são construídos ao longo de anos de maneira coletiva, sob a influência do contexto social e cultural, e ainda, que tais saberes são baseados em paradigmas de pensamento. Bartelmebs e Moraes (2012), reiteram que o ensino de Astronomia permite, à criança, o desenvolvimento do pensamento de que o conhecimento científico nunca está acabado. Desse modo, por meio do ensino da Astronomia se pode "desmistificar ideias de senso comum sobre fenômenos que acontecem no céu, libertando o aluno de certos temores e ignorância, como, por exemplo: os eclipses e o que eles causam, o aparecimento misterioso de objetos brilhantes e desconhecidos no céu" (LANGHI, 2016, p. 11).

Simon (2016) discorre que o ensino de Astronomia estimula o aluno a questionar, levantar hipóteses e ideias sobre aquilo que se observa e se discute, aproximando o que é abordado no contexto escolar daquilo que o aluno vivencia. Sob essa perspectiva, o presente estudo busca identificar indicativos da mobilização de teoremas em ação de conceitos de astronomia em alunos do $5^{\circ}$ ano do Ensino Fundamental de uma escola pública de Goioerê. O ambiente de pesquisa foi gerado a partir de um projeto de Astronomia desenvolvido em uma Escola Municipal de Ensino Infantil e Fundamental localizada no noroeste do Paraná.

Os dados para a pesquisa são provenientes da observação participante e notas de campo da pesquisadora, como também, das produções escritas e orais dos estudantes ao resolverem situações de Astronomia, que foram planejadas a partir de uma sequência didática. Esta pesquisa proporcionará identificar indicativos da mobilização de teoremas-em-ação de conceitos de Astronomia. Temos por hipótese que os estudantes dos anos iniciais podem mobilizar conceitos inadequados sobre Astronomia, como por exemplo, pode ocorrer uma 
distorção sobre o movimento da Terra em torno do Sol, pois do ponto de vista de um observador situado na Terra a impressão que há é a de que quem se movimenta é o Sol, ou pode ocorrer a impressão de que a cada noite há uma Lua diferente no céu, visto que a cada noite esse satélite natural possui uma aparência diferente, ou os alunos podem acreditar que as estações do ano são consequência da proximidade da Terra em relação ao Sol, e não ao seu eixo de inclinação, ou que os eclipses são místicos, entre outras coisas. Isso pode ocorrer em função de um processo de conceitualização falho por parte dos alunos, da formação incipiente que o professor pedagogo recebeu ao longo de sua graduação, dos conhecimentos prévios adquiridos ao longo da vida de alunos e professores, sem embasamento científico, e sim com base em crenças e por atualmente existirem diversas fontes de informação.

Diante do exposto, essa pesquisa buscou identificar teoremas em ação são mobilizados por uma turma de estudantes do quinto ano do Ensino Fundamental ao resolverem situações de Astronomia.

\section{REFERENCIAL TEÓRICO}

\subsection{A TeOria dos CAMPos Conceituais EnQuanto aporte teórico PaRa ANÁlise DOS DADOS}

A Teoria dos Campos Conceituais (TCC) é caracterizada como uma teoria didática, pois está situada num sistema que liga o saber, o aluno e o professor. A TCC proporciona o estudo das ações dos alunos e as condições de produção, registro e comunicação durante situações de aprendizagem. Ao professor, esta teoria fornece mecanismos para compreender as ações do estudante, como também subsídios para a organização dos conteúdos em sala de aula, de modo a privilegiar uma diversidade de situações.

Vergnaud (1990) destaca que a formação de um conceito, em diferentes domínios do pensamento racional, possibilita ao professor estimular e valorizar diferentes situações para auxiliar o processo de conceitualização. Os elementos que caracterizam a TCC tratam de um conhecimento sobre o conteúdo a ser ensinado e das relações desse conteúdo com as atividades que os alunos são capazes de realizar, o que possibilita compreender como aprendem os conceitos, em especial, neste trabalho estamos interessados em conceitos relacionados à Astronomia. Nas palavras do autor:

[...] a estrutura dos campos conceituais também é útil para auxiliar professores a organizar situações didáticas e intervenções, que dependem tanto da epistemologia da 
matemática quanto de uma melhor compreensão do processo de conceitualização dos estudantes (VERGNAUD, 2009, p. 83).

As situações mais proveitosas são as que relacionam vários conceitos, já que a TCC considera a existência de conceitos interligados, formando uma rede complexa. Neste sentido, o docente que compartilha esta ideia preocupa-se em elaborar situações problemas adequadas à relação de conceitos, aos debates e às representações utilizadas pelos alunos. É justamente uma das propostas da TCC, repensar as condições da aprendizagem conceitual.

Para Vergnaud (2009) a formação e o desenvolvimento de um conceito devem emergir a partir de situações problemas que levem em consideração: a representação e o conceito e, os invariantes operatórios (conceitos e teoremas em ação) na situação problema. Assim, um conceito é composto por uma terna de conjuntos ( $S, I, R)$, em que representam: $S$ - conjunto de situações que dão sentido ao conceito; I - conjunto de invariantes (objeto, propriedades e relações) sobre os quais ocorre a operacionalidade do conceito e, R - conjunto de representações simbólicas que permitem indicar e representar os invariantes.

O conhecimento de um indivíduo se encontra organizado em campos conceituais, sendo que um campo conceitual é compreendido como amplo conjunto de conceitos, situações e invariantes, interconectados, que reunidos permitem dar sentido às dificuldades que os alunos possuem na conceitualização do real, conceitualização esta, que é parte indissociável do desenvolvimento cognitivo do aluno. Além disso, o autor destaca que um conceito se forma a partir de diferentes tipos de situações, e cada situação se forma a partir de diferentes conceitos e desta forma, a compreensão e apropriação das propriedades de um conceito ou uma situação compõem um campo conceitual (VERGNAUD, 1990).

Para compreensão de campo conceitual o conceito de situação é importante. Uma situação é entendida como uma tarefa, sendo que toda situação complexa pode ser analisada como uma combinação de tarefas, ou seja, os processos cognitivos e as respostas do sujeito são funções das situações com as quais é confrontado e é a partir do confronto com elas e do domínio que progressivamente alcança sobre as mesmas que o sujeito molda os campos conceituais que constituem seu conhecimento (VERGNAUD, 1990).

Para o autor, quatro são os ingredientes de um esquema referente às situações, que se constituem por: (1) Metas e antecipações; (2) Regras de ação; (3) Invariantes operatórios: são os teoremas e conceitos em ação e o reconhecimento dos elementos pertinentes à ação e (4) Possibilidades de inferência. 
Dos quatro elementos apontados acima, apenas os invariantes operatórios são indispensáveis à conexão entre a situação que o sujeito enfrenta e a estratégia que ele possui para resolvê-la. Um teorema em ação é uma proposição que se supõe verdadeira sobre a situação e um conceito em ação é um objeto, um predicado ou uma categoria do pensamento tida como relevante a ela (MOREIRA, 2002, p. 3). Assim, o conceito em ação que um sujeito possui permite a ele identificar elementos conhecidos nas situações que enfrenta, enquanto que os teoremas em ação fornecem 'regras' que relacionam esses elementos e que permitem que o sujeito resolva determinada situação e aja.

Dessa forma, por mais que a TCC tenha sido, inicialmente, desenvolvida para o ensino de Matemática, especificamente o campo da adição e multiplicação, autores como Carvalho (2008), Scheffler (2011), Moreira (2002), Sousa e Fávero (2002), entre muitos outros, mostram que ela pode ser expandida para as mais diversas áreas do conhecimento mantendo as mesmas características e benefícios.

\subsection{UM OLHAR PARA A BASE NACIONAL COMUM CURRICUlaR}

A Base Nacional Comum Curricular (BNCC) é um documento norteador para a Educação Básica em território nacional, definida como "um documento que define o conjunto [...] de aprendizagens essenciais que todos os alunos devem desenvolver, ao longo das etapas e modalidades da Educação Básica, de modo a que tenham assegurados seus direitos de aprendizagem e desenvolvimento" (BRASIL, 2018, p. 7).

$\mathrm{Na}$ perspectiva deste documento, as aprendizagens, ditas essenciais, asseguram o desenvolvimento de dez competências gerais. Tais competências são compreendidas como: (1) mobilização de conhecimentos (conceitos e procedimentos), (2) habilidades (práticas, cognitivas e socioemocionais) e (3) atitudes e valores necessários para enfrentar situações complexas da vida cotidiana, bem como para exercício da cidadania.

Para o Ensino Fundamental, a BNCC se organiza em cinco áreas do conhecimento: Linguagens, Matemática, Ciências da Natureza, Ciências Humanas e Ensino Religioso. Sendo assim, no decorrer do Ensino Fundamental, a área de Ciências da Natureza possui a missão de alfabetizar cientificamente, permitindo ao aluno compreender e interpretar o mundo, e também transformá-lo. Nessa perspectiva, para direcionar a elaboração dos currículos de Ciências, a BNCC organiza as aprendizagens essenciais em três unidades temáticas: (a) Matéria e energia, que compreende o estudo de materiais e suas transformações; (b) Vida e evolução, que propõe 
o estudo de questões relacionadas aos seres vivos e (c) Terra e Universo, que traz a compreensão de características da Terra, do Sol, da Lua e de outros corpos celestes.

Assim, observa-se que a área de Ciências da Natureza, busca assegurar a possibilidade que os alunos desenvolvam um novo olhar sobre o mundo, através de intervenções conscientes e baseadas na sustentabilidade e bem comum.

\section{MÉTODOS}

\subsection{ASPECTOS METOdológicos}

Esta pesquisa se pauta na abordagem qualitativa, segundo a qual as questões a serem investigadas são estabelecidas com o "objetivo de investigar os fenômenos com toda a sua complexidade e contexto natural" (BOGDAN, BIKLEN, 1994, p. 16). Os dados obtidos pelo investigador devem ser analisados de maneira detalhada, para que seja possível identificar o porquê de tal informação ser expressa de determinada forma.

Sob essa perspectiva, os autores apresentam cinco características pertencentes a investigação qualitativa: (1) a fonte de dados é o ambiente natural, no qual o investigador é o instrumento principal; (2) a investigação qualitativa é descritiva, visto que os dados não são numéricos, mas sim palavras ou imagens, incluindo "entrevistas notas de campo, fotografias, vídeos, documentos pessoais, memorandos e outros registros oficiais" (BOGDAN, BIKLEN, 1994, p. 48); (3) o investigador qualitativo se preocupa mais com o processo do que com o resultado; (4) análise de forma indutiva dos dados, ou seja, os dados não são coletados a fim de confirmar hipóteses prévias e (5) o significado é de extrema importância, isto é, perspectivas participantes. Os investigadores qualitativos se preocupam em apreender as diferentes perspectivas. Apesar de elencarem cinco características para a investigação qualitativa, os autores ressaltam que para uma pesquisa ser considerada qualitativa ela não precisa necessariamente conter todas as características citadas.

Dessa forma, inicialmente realizamos um levantamento bibliográfico de teses e dissertações presentes no Banco de Teses e Dissertações sobre Educação em Astronomia (BTDEA) e na Biblioteca Digital Brasileira de Teses e Dissertações (BTDT) a respeito das pesquisas em Astronomia desenvolvidas nos anos iniciais do Ensino Fundamental (PACHECO, ZANELLA, 2019). Em seguida, elaborou-se uma sequência didática com base nos conteúdos sugeridos pela BNCC para os anos iniciais do Ensino Fundamental e Teoria dos Campos Conceituais. Nessa perspectiva, as sequências didáticas são os instrumentos que possibilitam 
aprimorar a atuação do professor em sala de aula, como resultado de um conhecimento mais profundo das variáveis que intervêm e do papel que cada uma delas têm no processo de aprendizagem dos estudantes (ZABALA, 1998).

Uma sequência didática pode ser elaborada a partir de quatro unidades didáticas ou sequências, que são generalizáveis. Em nossa pesquisa escolhemos trabalhar com a Unidade 4, pois ela permite ao educador: (a) determinar os conhecimentos prévios do aluno, (b) propor o conteúdo de forma significativa funcional e (c) provocar conflito cognitivo e atividade mental. Além disso, essa é a unidade em que o professor tem a possibilidade de apenas mediar o conteúdo, o que dá mais liberdade para o aluno agir, refletir e ser o construtor de seu conhecimento (ZABALA, 1998).

A sequência didática foi organizada em formato de uma apostila, que se constituiu como uma fonte de coleta de dados. Ademais, gravações de áudio e entrevistas individuais ou em grupos também constituíram a fonte de coleta de dados. A pesquisa ocorreu dentro do ambiente escolar dos investigados, em uma Escola Municipal de Educação Infantil e Fundamental, no noroeste do Paraná, na forma de encontros semanais. O horário utilizado para os encontros foi o horário de aula dos estudantes, de acordo com a disposição dada pela professora da turma, ocorrendo no mínimo uma vez por semana, com duração de 2 horas aulas cada um.

Ressalta-se que a aplicação da sequência didática constituí o trabalho de conclusão de curso de uma acadêmica do curso de Física da Universidade Estadual de Maringá. A aplicação resultou em nove encontros, que abrangeram os temas: Sol, uma estrela; Lua e suas fases e Sistema Solar. Os resultados apresentados neste presente artigo referem-se a quatro atividades (situação A, B, C e D) que permitiram a identificação de teoremas-em-ação referentes ao tema Sol, uma estrela. As aulas aplicadas e as atividades realizadas pelos estudantes foram descritas, com auxílio de gravações de áudio captadas durante a realização das tarefas, e uso TCC, apresentamos uma análise descritiva e interpretativa das ações dos alunos que apresentaram teoremas-em-ação, identificados em quadros.

\section{ANÁLISE E DISCUSSÃo DE DADOS}

As atividades foram desenvolvidas por dezoito (18) estudantes colaboradores desta pesquisa, que abrange uma turma do quinto ano, os quais foram organizados em grupos nomeados por Grupo A, B, C e D, nos quais os alunos foram identificados pela inicial maiúscula do grupo seguida de um número, como por exemplo, os alunos do Grupo A estão representados por A1, A2, A3 e assim por diante. São utilizadas nessa seção siglas referentes ao grau de 
pertinência do teorema em ação identificados, sendo TAF (teorema em ação falso) e TAV (teorema em ação verdadeiro). São distinguidos devido aos numerais que seguem essas abreviações que estão dispostos devido a ordem em que foram sendo identificados.

Antes da primeira atividade ser aplicada, a pesquisadora direcionou questionamentos a respeito do Sol para os estudantes, com o intuito de realizar um levantamento de seus conhecimentos prévios. A condução dessa pequena discussão pode ser seguida no diálogo abaixo:

Pesquisadora: O que vocês podem me dizer sobre o Sol?

$\mathrm{C} 1$ : Ele é uma estrela.

A5: Que o Sol é uma bola muito grande.

B3: É uma bola quente.

Pesquisadora: O que mais?

A3: Que ele é o mais quente do Universo.

C6: Ele é o terceiro mais grande.

A5: Não, ele é o primeiro.

D1: Não é não.

A5: Ele é o primeiro sim. Ele é mais grande que tudo.

Professora da UEM: Ele é o maior de todos?

C4: Não, ele não é o mais grande. O mais grande é Júpiter.

C6: Tem duas estrelas que são mais grandes que ele.

A3: Ele é o planeta mais grande.

A6: Professora, ele é o planeta mais grande do Sistema Solar.

Dessa forma, após essa discussão inicial foi entregue a cada um dos alunos uma apostila, resultado da construção da sequência didática, e foi solicitado que eles respondessem as questões referentes ao Sol. Sendo enfatizado que neste momento que não havia resposta certa ou errada, uma vez que a intenção era saber o que eles pensavam, ou seja, fazer um levantamento prévio de seus conhecimentos. De acordo com Moreira (2002), as concepções prévias dos alunos contêm teoremas-em-ação, que podem evoluir para conceitos científicos verdadeiros ou que devem ser abandonados para que conceitos corretos possam ser construídos.

Louzada et al (2015, p.8) ainda destaca a importância das concepções alternativas para o processo de aprendizagem, para os autores:

Para que uma estratégia de ensino se mostre eficiente é necessário levar em conta o conhecimento prévio dos estudantes sobre o que se pretende ensinar, caso contrário os alunos terão dificuldades em assimilar as novas informações. Além disso, suas concepções alternativas permanecerão e outras, decorrentes das anteriores, poderão até surgir (LOUZADA et al, 2015, p. 8). 
O diálogo apresentado anteriormente representa a mobilização dos alunos para compreender os problemas que estavam sendo lançados pela pesquisadora e a partir disso buscar uma solução. Em seguida, por meio das questões dissertativas os alunos foram confrontados com situações que se referiam a discussão inicial. No entanto, apenas algumas afirmações feitas por eles foram utilizadas para a resolução das tarefas.

\subsection{ATIVIDADE A: NO PRIMEIRO QUADRADO DESENHE COMO VOCÊ ACREDITA QUE SEJA O SOL, NO SEGUNDO QUADRADO DESENHE COMO VOCÊ ACREDITA QUE SEJA UMA ESTRELA.}

A primeira atividade solicitava que os alunos desenhassem o Sol da forma que imaginavam que ele realmente é, e a forma com que imaginavam que uma estrela realmente é. O objetivo dessa questão era observar se os estudantes possuíam o conceito de que o Sol é uma estrela. Portanto, ao desenhar o Sol eles estariam desenhando uma estrela e vice-versa, assim não deveria existir, necessariamente, diferenças entre os desenhos.

Observou-se que, entre as 18 respostas analisadas apenas o estudante D1 desenhou tanto o Sol quanto a estrela como círculos, representando esferas, 10 estudantes representaram o Sol como um círculo do qual saem raios e a estrela como uma estrela de pontas e 7 estudantes representaram o Sol com formato circular, sem raios, e a estrela como sendo de pontas. A partir disso, as respostas foram categorizadas em três grupos: (1) Sol e estrela iguais; (2) Sol circular com raios e estrela de ponta e (3) Sol circular sem raios e estrelas de pontas. Abaixo, no Quadro 1, está a resposta dos alunos D1, B2 e A3, representando cada uma das categorias, respectivamente. 
Quadro 1 - Categorias de respostas apresentadas pelos estudantes para atividade A

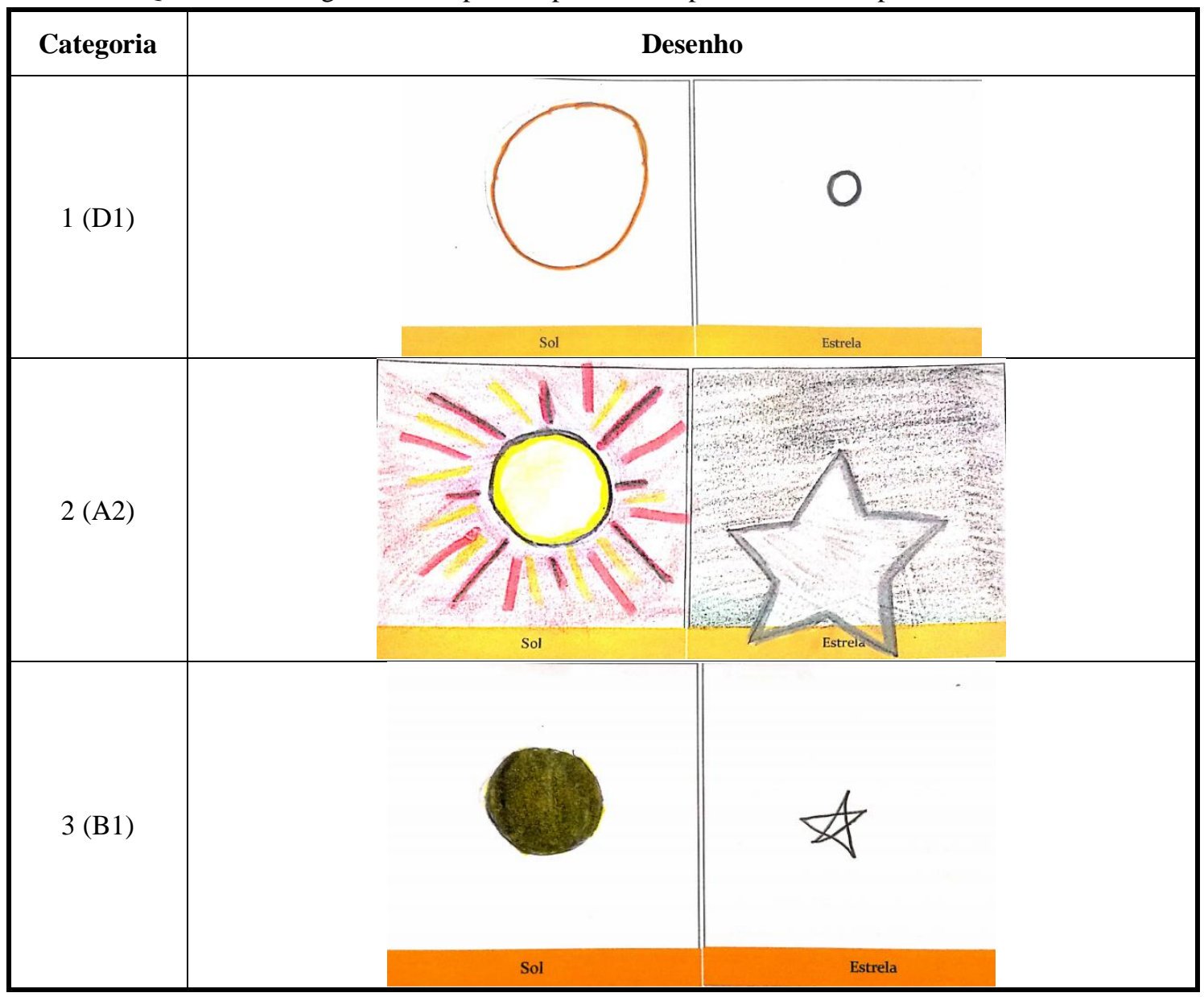

Fonte: Resultado da pesquisa.

Esses desenhos feitos pelos alunos são representações. Para Moreira (2002), quando Vergnaud, se refere a representações, descreve um sistema simbólico que significa algo para o sujeito. Assim, a construção do conhecimento ocorre a partir da progressiva construção de representações mentais "homomórficas à realidade para alguns aspectos e para outros não" (VERGNAUD, 1990, p. 22). Tais representações são computáveis, podendo estar corretas ou erradas, serem vagas ou precisas, implícitas ou explícitas, resumidamente, substitutos da realidade, e dessa forma, proposições compreendidas como verdadeiras pelo sujeito, teoremasem-ação.

Quando questionados sobre os desenhos, o aluno D1, representante da Categoria 1, Sol e estrela iguais, explicou que sabia que o Sol era uma estrela e que estrela não era de pontas. Veja sua justificativa:

Pesquisadora: Quando eu perguntei se a sala sabia alguma coisa sobre o Sol, você disse que o Sol era uma esfera de pedra. De onde veio essa ideia de que o Sol era esfera de pedra? 
D1: É que eu pensei ... é que em um vídeo tinha uma pedra que ela era de carvão que pegou fogo daí eu pensei que com a batida de um asteroide soltou faísca e o Sol pegou fogo.

Pesquisadora: Então o Sol seria uma pedra igual ao carvão?

D1: Aham (sic).

Pesquisadora: Interessante. Outra coisa, no primeiro desenho do Sol e da Estrela, você desenhou a estrela redonda, por quê?

D1: Eu vi num desenho em que uma menina conseguia ver as coisas como elas são, aí ela foi em um lugar em que ela viu que as estrelas não são de ponta, esse é o jeito que elas brilhavam, daí vem aquelas pontas, aqueles brilhos... por causa da luz que elas faziam brilhando.

Além disso, notou-se que o aluno C6, apesar de representar a estrela e o Sol com formato circular, fez questão de representar o Sol como sendo maior. Em relação aos alunos que compõem a Categoria 2, Sol circular com raios e estrela de ponta, e Categoria 3, Sol circular sem raios e estrela de pontas, quando questionados a respeito de seus desenhos deram duas respostas distintas: ou que o Sol era um planeta ou uma estrela.

Pesquisadora: O que vocês podem me dizer sobre o Sol?

A5: Ele é mais grande que tudo.

Professora da UEM: Ele é o maior de todos?

C4: Não, ele não é o mais grande. O mais grande é Júpiter.

D1: Tem duas estrelas que são mais grandes que ele.

A3: Ele é o planeta mais grande.

A6: Professora, ele é o planeta mais grande do Sistema Solar.

Pesquisadora: Então, como é o formato de uma estrela? Da estrela de verdade.

B3: Uma estrela de verdade? Tipo o Sol?

Pesquisadora: Isso. Como o Sol é?

B4: Redondo.

Pesquisadora: Então, por que vocês acham que vocês desenharam o Sol de um jeito e a estrela de outro?

B4: Ah, isso é porquê ... Professora é que nos filmes tem estrelinha de ponta...

B3: Quando a gente olha no céu a estrela não é redonda. É igual a estrela de ponta!

$[\ldots]$

Pesquisadora: Quando a gente pensa: o Sol é uma estrela e é esférico, por que a gente representa a estrela como sendo de pontas?

A5: Ah, a gente vê em desenhos, livros e outras coisas que fazem a estrela assim.

A partir da análise dos desenhos e dos diálogos entre os alunos, bem como entre alunosprofessor foram identificados alguns teoremas-em-ação que podem ser vistos no quadro 2 abaixo. 
Quadro 2 - Teoremas-em-ação identificados durante a atividade A

\begin{tabular}{|l|l|}
\hline \multicolumn{1}{|c|}{ Teorema-em-ação } & \multicolumn{1}{c|}{ Justificativa } \\
\hline $\begin{array}{l}\text { TAF1 - o Sol é o maior corpo } \\
\text { celeste existente. }\end{array}$ & $\begin{array}{l}\text { Os estudantes afirmaram diversas vezes, tanto na discussão inicial com } \\
\text { toda a sala, quanto nas entrevistas em grupos menores, que o Sol é o } \\
\text { maior do Universo. }\end{array}$ \\
\hline TAF2 - o Sol é um planeta. & $\begin{array}{l}\text { Quando os estudantes comparam o tamanho entre o Sol e Jupiter, } \\
\text { afirmando que o planeta é maior ou que o Sol é maior, fica implícito } \\
\text { que eles consideram que ambos são o mesmo tipo de corpo celeste. }\end{array}$ \\
\hline $\begin{array}{l}\text { TAF3 - o Sol é uma esfera de } \\
\text { pedra. }\end{array}$ & $\begin{array}{l}\text { O estudante D1 defende a ideia de que o Sol é uma esfera de pedra ou } \\
\text { carvão. Para tanto, ele possui uma explicação bem embasada de como } \\
\text { o carvão queima e o porquê de o Sol "queimar", levando-o a concluir } \\
\text { que ambos devem ser compostos pelo mesmo material }\end{array}$ \\
\hline TAF4 - o Sol não é uma estrela. & $\begin{array}{l}\text { Ao desenharem o Sol e a estrela qualquer de maneiras distintas fica } \\
\text { implícito que os estudantes não consideram o Sol como sendo uma } \\
\text { estrela. }\end{array}$ \\
\hline $\begin{array}{l}\text { TAF5 - as estrelas possuem a } \\
\text { forma de estrela de pontas. }\end{array}$ & Alguns estudantes verbalizam que o Sol é uma estrela. \\
\hline TAV1 - o Sol é uma estrela. & Font Resultado da pesquisa \\
\hline
\end{tabular}

Fonte: Resultado da pesquisa.

Ao questionar os estudantes sobre o que é o Sol (estrela, planeta...) foi solicitado que representassem o sol e uma estrela, embora seja duas situações diferentes, exigem a mobilização de conceitos semelhantes (o que é estrela e o que não é). Veja, uma vez que parte dos estudantes afirmaram durante a discussão que o Sol é uma estrela, esperava-se que esses mesmos estudantes não fizessem distinção em seus desenhos. Porém, como apresentado anteriormente, não foi o que aconteceu, como nota-se por meio dos TAF4 e TAF5. Percebe-se então a influência de meios externos sob a representação do astro celeste.

Finalizada a etapa de levantamento de conhecimento prévio dos estudantes, iniciou-se a explicação da professora, que foi iniciada com a observação do Sol. Utilizando filtros para proteger os olhos os estudantes foram levados até a parte externa da sala de aula para que pudessem ver como o Sol realmente se parece. Realizou-se todas as explicações de segurança enfatizando que eles não deveriam tentar observar o Sol se não estivessem com o filtro protetor.

Em seguida, os alunos foram conduzidos de volta a sala. Já dentro da sala de aula questionamentos a respeito da observação foram direcionados aos estudantes.

Pesquisadora: Pessoal, o Sol é do jeito que vocês imaginavam?

Todos: NÃO...

A1: É uma bolinha amarelinha. Muito legal.

C3: É pequenininho.

B5: Não tem raios saindo dele igual nos desenhos...

A4: Tem uma cor verde... 
Professora: A cor que vocês viram é por causa do filtro protetor, ficou próximo ao amarelo, mas algumas pessoas viram uma cor meio esverdeada.

B2: Professora, parecia a Lua de noite.

Professora: Em relação ao tamanho, vocês esperavam algo menor ou maior?

Todos: Menor/Maior (falaram todos ao mesmo tempo)

A atividade de observação e a discussão posterior permitiu aos estudantes confrontar suas expectativas e a realidade, uma vez que Moreira (2002), discorre que para TCC a construção do conhecimento não é um processo linear, mas possui retrocessos, rupturas, continuidades e avanços.

Realizada essa discussão exibiu-se uma imagem aproximada do Sol e suas características básica enfatizando que o Sol é uma estrela e que é a estrela mais próxima da Terra. Além disso, uma bola de isopor pintada com as cores da imagem foi mostrada para explicar para os estudantes que apesar de eles terem observado um "círculo", na verdade o Sol é esférico, porém da nossa posição não conseguimos ver as três dimensões. Exibiu-se, também, o vídeo "Comparação do tamanho das estrelas", que mostrava o planeta Terra e várias estrelas, incluindo o Sol, uma do lado da outra.

Os alunos relataram estarem surpresos com o vídeo, riam e ficavam impressionados a cada estrela "maior" que aparecia, pois não imaginavam que poderia haver corpos celestes tão grandes. Sobre a temperatura do Sol e o vídeo os alunos expressaram:

B1: A gente ia derreter se fosse lá.

B2: Professora a gente (ser humano) nunca foi no Sol né!

Professora: Não, o ser humano nunca foi até o Sol. Mas já enviamos sondas para perto do Sol.

D1: Tem um robozinho lá né professora.

Professora: No Sol não, mas tem um robô no planeta Marte.

B1: As outras estrelas também são quentes?

Professora: Então o Sol é a maior estrela?

Alunos: Não!!

Professora: Qual a única estrela que nós conseguimos visualizar durante o dia?

Alunos: O Sol!

Professora: Mas há estrelas maiores?

Alunos: Sim!!

B3: é verdade que as estrelas são infinitas?

A4: e a galáxia?

D2: A Lua é maior que o Sol?

Outros alunos: Não. 
Antes da realização das atividades pós-explicação a aula foi interrompida pela coordenadora que solicitou que os alunos fossem liberados para o intervalo, pois a escola estava testando um novo esquema, realizar o intervalo das crianças maiores ao mesmo tempo que as crianças menores. Os estudantes foram dispensados. Como a aula anterior havia sido interrompida e finalizada de forma diferente do planejado. Iniciou-se o primeiro encontro com uma revisão oral do conteúdo visto na semana anterior.

Professora: O que nós estávamos estudando semana passa?

C1: Sobre o Sol!

D2: As estrelas!

Professora: Isso mesmo! Mas o que nós estudamos sobre o Sol?

C2: Que tem estrela mais grande que ele.

A5: A gente foi lá fora e olhou para ele.

C1: Que ele é uma estrela!

Professora: Então nós estudamos que o Sol é uma...

Alunos: Estrela!

Professora: Estudamos também que o Sol não é a maior estrela do Universo.

D1: Não mesmo, existem outras estrelas maiores que ele.

Professora: e o que mais?

C4: O Sol é uma bola.

Professora: Isso, o Sol é redondo, esférico. E por que não vemos as outras estrelas durante o dia?

Alunos: Por causa da luz do Sol.

Professora: Isso mesmo, e porque o Sol está mais...

Alunos: perto da Terra.

\subsection{ATIVIDADE B: DESENHE NOVAMENTE O SOL E UMA OUTRA ESTRELA.}

Essa questão solicitava que os estudantes desenhassem o Sol e uma outra estrela. O objetivo era observar se ocorreu o rompimento da ideia que os estudantes tinham de que o Sol e um estrela são corpos celestes diferentes. Esperava-se que os estudantes representassem ambos com círculos, substituindo a ideia de estrela como sendo o desenho de pontas ( $\star$ ).

Observou-se que, entre as 18 respostas analisadas, 14 estudante desenharam o Sol e a estrela como circulares, dentre esses quatorze estudantes 8 representaram o Sol maior que a estrela, 4 o Sol do mesmo tamanho que a estrela e 2 a estrela maior que o Sol; 4 estudantes mantiveram a representação anterior desenharam o Sol como um círculo e a estrela como sendo de pontas. A partir disso, categorizou-se as respostas em dois grandes grupos: (1) Sol circular e estrela de pontas; (2) Sol e estrela circulares, com as subcategorias: (2a) Sol maior que a 
estrela, (2b) Sol e estrela do mesmo tamanho, (2c) estrela maior que o Sol. Abaixo está a resposta dos alunos A2, C6, B4 e B1, representando cada uma das categorias e subcategorias.

Quadro 3 - Respostas apresentadas por alguns alunos para a atividade B

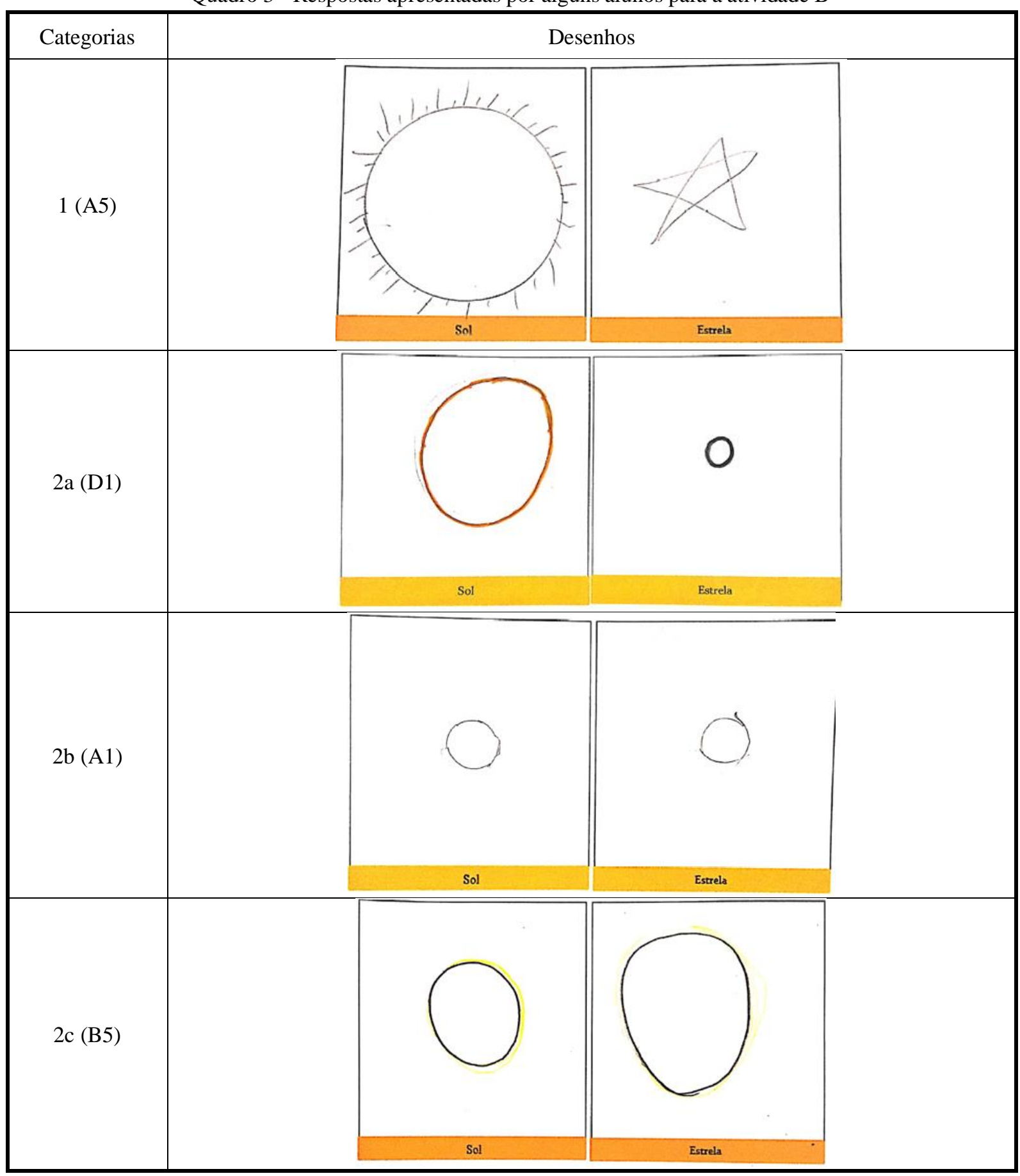

Fonte: Resultado da pesquisa.

Após a observação do Sol com o aparato correto, todos os alunos descreveram o Sol por meio de objetos circulares (referem-se: a bola, círculo, esfera). No entanto, nas representações 
do Sol que fizeram, 5 estudantes utilizaram-se da primeira representação que fizeram da estrela com pontas. Abaixo encontra-se trecho da entrevista desses estudantes:

E: Vocês lembram que na aula passada na atividade da apostila eu pedi para que vocês desenhassem o Sol e uma estrela. Então, como é o formato de uma estrela? Da estrela de verdade.

A5: Uma estrela de verdade? Tipo o Sol?

E: Isso. Como o Sol é?

B3: Redondo.

E: Muito bem. Naquele vídeo que a gente viu na sala: como eram as outras estrelas?

A5: Ah ... uma maior que a outra. Tipo, tem uma estrela maior que o Sol, e outra maior, e outra maior ...

E: E como era os formatos dessas estrelas?

B3: Redonda

E: Hum ... no final da aula vocês desenharam pela segunda vez o Sol e uma estrela. Como vocês desenharam?

B3: Ah eu desenhei assim (fazendo o desenho da estrela de pontas com os dedos sobre a mesa)

A5: Eu desenhei assim também professora.

E: Uma estrela de pontas então. As três desenharam do mesmo jeito... Mas olha só, a gente acabou de conversar sobre isso, e vocês me falaram que o Sol é redondo, que as estrelas são redondas. Então, por que vocês acham que vocês desenharam o Sol de um jeito e a estrela de outro?

B3: Ah isso é porquê ... Professora é que nos filmes tem estrelinha de ponta...

A partir desse diálogo pode-se evidenciar que os estudantes transformaram o TAF4 " $o$ Sol não é uma estrela" e o TAF5 "as estrelas possuem a forma de estrela de pontas" evoluíram para um teorema-em-ação verdadeiro, pois agora reconhecem o Sol como estrela, tanto que durante a entrevista eles "corrigem" a professora ao dizerem "uma estrela de verdade? Tipo o Sol?’. Entretanto, esses mesmos alunos mantém a representação de estrela como sendo o desenho de pontas.

Segundo Moreira (2002), o termo representações se refere ao sistema simbólico que tem significado para o sujeito que o ajuda a na aquisição de conceitos, daí a importância das representações/desenhos dos estudantes. A partir desta perspectiva, os diálogos e desenhos evidenciaram que os estudantes possuem, agora, duas representações para o conceito estrela: (1) estrela como um corpo celeste esférico, referindo-se ao conceito científico e (2) estrela de pontas, referindo-se à representação cotidiana de estrela. $\mathrm{O}$ quadro 4 apresenta o teorema-emação verdadeiro, mobilizado pelos estudantes, mas com indicativos de que houve uma ruptura, uma mudança. 
Quadro 4 - Teorema-em-ação para a atividade B

\begin{tabular}{|c|l|}
\hline \multicolumn{1}{|c|}{ Teorema-em-ação } & \multicolumn{1}{c|}{ Justificativa } \\
\hline TAV2 - as estrelas têm formato esférico. & $\begin{array}{l}\text { Os estudantes entendem que estrelas reais possuem } \\
\text { formato esférico, e que o Sol, por ser uma estrela, } \\
\text { também possui formato esférico. }\end{array}$ \\
\hline
\end{tabular}

Fonte: Resultado da pesquisa.

Após a aplicação desta atividade, ocorreu um intervalo de quatro semanas para a realização da Atividade $\mathrm{C}$, enquanto outras ações foram realizadas neste intervalo. Ressalta-se que o segundo encontro teve como foco o tema Sol, uma estrela, enquanto o sexto encontro discutiu aspectos do Sistema Solar.

\subsection{ATIVIDADE C: DESENHE A LUA EM UMA NOITE ESTRELADA}

Esta atividade solicitava que os estudantes desenhassem dentro da área demarcada a Lua em uma noite estrelada. $\mathrm{O}$ objetivo era observar se os alunos entendiam que independente da fase em que a Lua esteja é impossível ver estrelas que estejam na região de trás do satélite natural, como observado no Figura 1. Além disso, buscou-se observar também como os alunos representariam as estrelas, como estrela de ponta ou uma esfera, visto que discutimos esse tópico em aulas anteriores. Note que não se especificou nenhuma fase, portanto, eles tiveram liberdade quanto a isso.

Quadro 5 - Desenhos esperados para a atividade C, onde o quadrante superior esquerdo representa a Lua Cheia, o quadrante superior direito a Lua Crescente, o quadrante inferior esquerdo a Lua Nova e o quadrante inferior direito a lua minguante

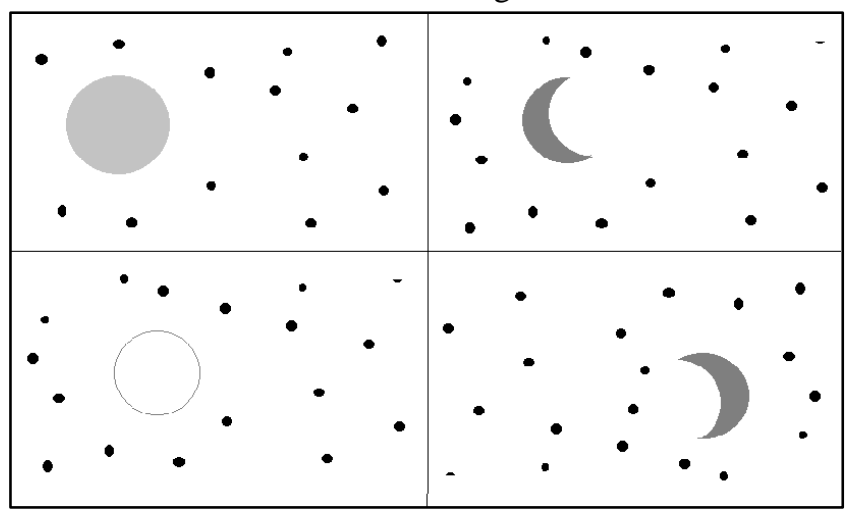

Fonte: Resultado da pesquisa.

Porém, dos 18 estudantes participantes, apenas um estudante fez a representação considerando as estrelas como esferas, ilustrado na figura 1. Por mais que haja o entendimento de que nos mais diversos meios de comunicação ou visuais as estrelas sejam representadas como a estrela de pontas, esperava-se que fossem representadas aqui como esferas, ou círculos, uma vez que em aulas anteriores os estudantes mostraram possuir duas representações para o termo estrela, a representação científica e a do cotidiano. 
Quadro 6 - Desenhos feitos pelos alunos para a atividade C

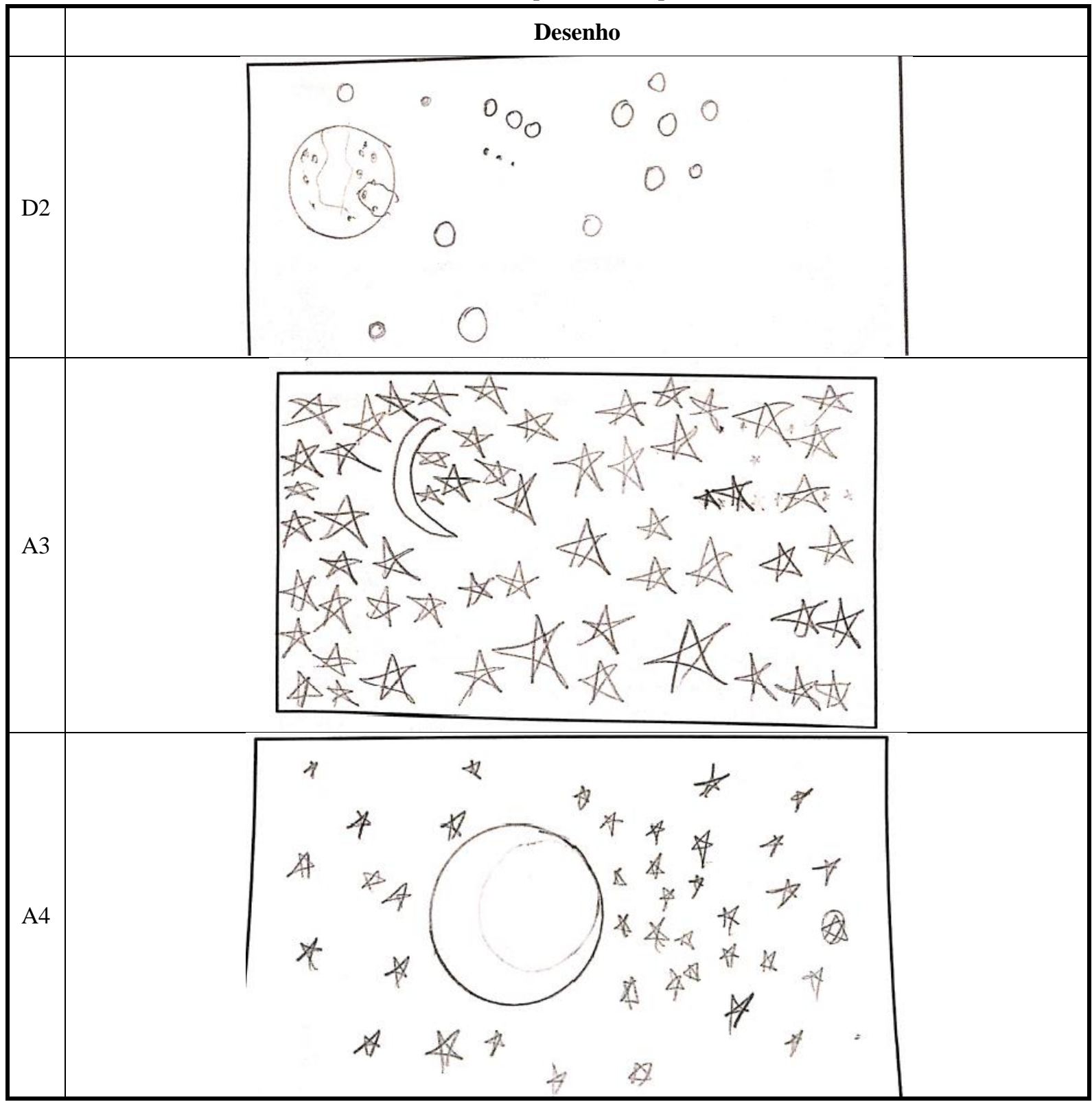

Fonte: Resultado da pesquisa.

A partir dos desenhos acima, observa-se que mesmo com as situações propostas a maioria dos alunos (17/18) não desestabilizaram completamente o TAF4, "o Sol não é uma estrela" e o TAF5, "as estrelas possuem a forma de estrela de pontas". Além disso, nota-se a ideia equivocada de alguns estudantes ao desenharem estrelas na área que deveria ser destinada a parte escura da Lua, e, portanto, a parte que não conseguimos observar dependendo da fase em que a Lua se encontra. 


\subsection{ATIVIDADE D: Como é o Sistema Solar? Na FOlHa QUE SERÁ ENTREgUe DESENHE O SISTEMA SOLAR.}

Esta atividade solicitava que os alunos representassem na folha de papel como acreditavam ser o Sistema Solar. Das 18 representações, 9 foram representações dos planetas enfileirados, 4 representaram o Sol ao centro com os demais planetas o orbitando e 6 representaram diversas estrelas de pontas e o Sol esférico. O Quadro 6 apresenta alguns exemplos.

Quadro 7 - Desenhos feitos pelos estudantes para atividade D

Alunos




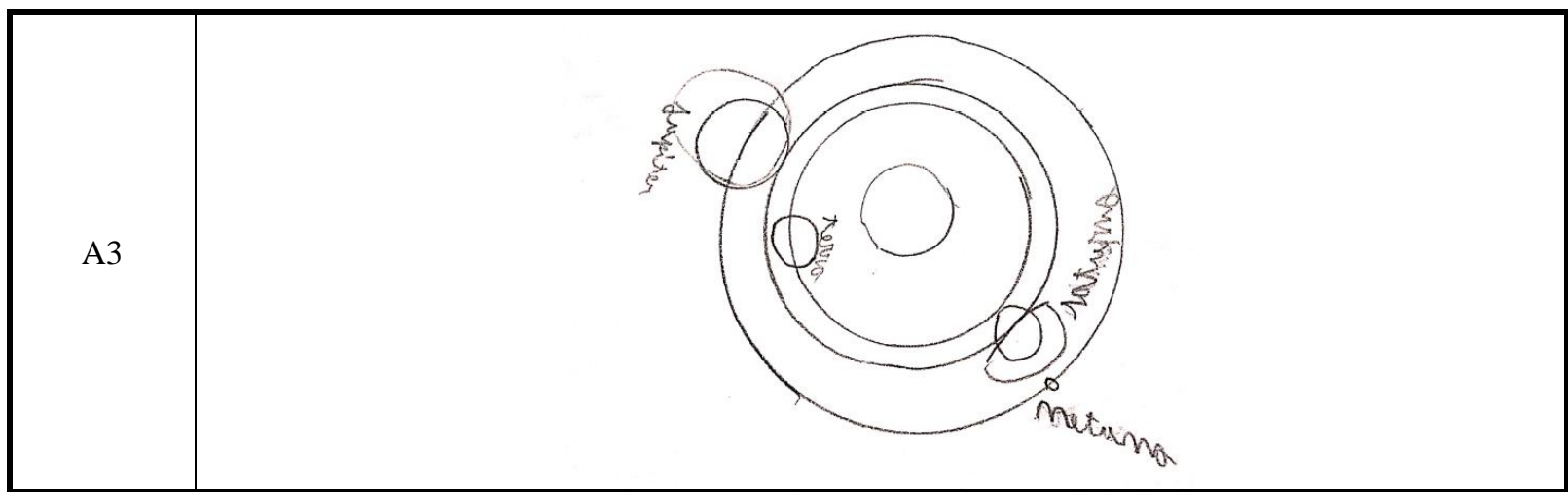

Fonte: Resultado da pesquisa.

Diante dessa situação, chama-nos a atenção o fato de que no decorrer das aulas e entrevistas individuais, já expostas acima, os estudantes repetem e confirmam que o Sol é uma estrela e que estrelas são esféricas. Entretanto, isso não basta para que suas representações sejam trocadas. A partir da análise das respostas dadas, notou-se que o estudante D1 manteve sua representação do Sol/estrela como uma esfera nas atividades A, B e D, mas não na atividade C. Quinze (15) estudantes mudaram suas representações de estrela de pontas para estrela esférica entre a primeira representação, atividade A, e representação dois, atividade B. Desses quinze estudantes sete (7), retornaram à representação de estrela de pontas na atividade vinte e cinco (25), o que mostrou que a desestabilização do teorema-em-ação falso cinco foi apenas momentânea, prevalecendo a representação prévia que possuíam. E apenas a estudante D2 representou estrelas como esferas na atividade $\mathrm{C}$.

Com base nas declarações dadas durantes a entrevistas, observou-se que os estudantes mencionaram várias vezes que suas representações estavam intimamente ligadas as representações de estrelas que viam em desenhos, objetos do dia a dia, entre outras coisas. $\mathrm{Ou}$ seja, nota-se aqui uma forte influência de representações não científicas de objetos celestes.

O mesmo foi observado por Borges (2018), ao estudar modelos mentais sobre Sistema Solar. Borges (2018) em seus dados também obteve, inicialmente, um grande número de representações de estrelas de pontas, que se repetiram, em uma etapa posterior de sua pesquisa, porém em número reduzido. A autora justificou tal representação feita por seus alunos devido ao fato de esse modelo ser reforçado por materiais didáticos, paradidáticos e literários, escolhidos para escolas

\section{CONSIDERAÇões Finais}

Considerada uma das mais antigas ciências, a Astronomia é objeto de fascínio e curiosidade. Seu ensino oportuniza uma abordagem interdisciplinar, promove a compreensão 
de que os saberes científicos são desenvolvidos ao longo de anos por diversos cientistas e que são afetados por fatores externos, como contexto social e cultural. Além disso, a Astronomia desperta a curiosidade dos estudantes, que são estimulados a questionar, elaborar hipóteses e aproximar o que estudam de seu cotidiano. Então, sob o referencial teórico da Teoria dos Campos Conceituais, esse trabalho buscou identificar teoremas-em ação são mobilizados por uma turma de estudantes do quinto ano.

Para tanto, foi desenvolvida uma apostila, resultado de uma sequência didática, para coleta de dados. Neste artigo, analisamos somente quatro das atividades propostas, a saber: atividades $\mathrm{A}, \mathrm{B}, \mathrm{C}$ e $\mathrm{D}$, as quais referiam-se a diferentes tópicos, porém permitiram a identificação de teoremas em ação sobre o formato das estrelas. As atividades analisadas compreendiam a elaboração de desenhos de representação do Sol e uma outra estrela, representações da Lua em uma noite estrelada e representações do Sistema Solar.

Além disso, entre a execução das atividades, os estudantes tiveram aulas de Astronomia, nas quais realizaram debates sobre os temas, experimentos, observação do Sol, assistiram a vídeos, participaram de dinâmicas de revisão do conteúdo, entre outras. A diversidade de atividades se deu baseada na TCC, segundo a qual um conceito não se forma em uma única situação e uma situação não compreende apenas um conceito.

Diante disso, foram identificados, ao todo, sete teoremas-em-ação, os quais cinco são falsos e dois são verdadeiros, relacionado ao tópico “o Sol é uma estrela”. Dentre os teoremas em ação classificados como falsos estão: “o Sol é o maior corpo celeste existente; o Sol é um planeta; o Sol é uma esfera de pedra; O Sol não é uma estrela $\&$ as estrelas possuem a forma de estrela de pontas". Dentre os teoremas-em-ação identificados como verdadeiros estão: "o Sol é uma estrela e as estrelas têm formato esférico". Notou-se que inicialmente, situação A, apenas um estudante representou o Sol e uma outra estrela como corpos esféricos. Na situação B, 13 estudantes mudaram sua representação de estrela de pontas para estrela esférica. Na situação C, apenas um estudante novamente, representou as estrelas como esféricas e na situação D, quinze estudantes representaram suas estrelas como esféricas.

Além disso, durante a execução das atividades, foi evidente que a maior dificuldade encontrada pelos alunos, para a resolução dos exercícios, foi a interpretação de texto. Eles se expressavam muito bem quando as atividades eram feitas de maneira oral, mas não conseguiam desenvolver suas ideias quando era algo escrito, sendo necessário nosso auxílio para esclarecimento de perguntas. Em relação às dificuldades de contextualização, notou-se que os 
estudantes tinham dificuldades de superar suas ideias prévias que tinham como verdade, além de confundirem conceitos astronômicos como planetas e estrelas.

Dessa maneira, consideramos que ao analisar aulas e situações de Astronomia sob a Teoria dos Campos Conceituais permite ao professor identificar as dificuldades de conceitualização apresentadas pelos estudantes e compreender como seu processo de conceitualização está evoluindo com o passar do tempo. Veja, Vergnaud defende que a conceitualização é um processo longo. Mesmo que ao final, durante a situação D, alguns alunos mantivessem a representação de estrela de pontas, notou-se que durante o processo, isto é, atividades $\mathrm{B}$ e $\mathrm{C}$, esses mesmos alunos mudaram suas representações, o que mostra que a desestabilização dos teoremas-em-ação foi iniciada, mas ainda é um processo e necessita de mais tempo.

Outro ponto a ressaltar é o fato de que a diversidade de situações foi determinante para a contínua motivação e engajamento dos estudantes. Foi determinante também para a coleta de informações que permitiram a compreensão, por parte da pesquisadora, do desenvolvimento dos alunos. Foram identificados problemas que extrapolam a sala de aula, mas que influenciam a construção de conceitos e representações por parte dos estudantes. Essa identificação nos ajuda na hora de formular livros didáticos, selecionar imagens para aulas, por exemplo. Por fim, a TCC já foi utilizada em diversas áreas, como Matemática, Física e Biologia, mas ainda é pouco explorada na área da Astronomia. Por isso, sugerimos que para pesquisas futuras a utilização de TCC seja uma das ferramentas para o ensino de Astronomia.

\section{REFERÊNCIA}

ANDERSSEN, Luc. Comparação do tamanho das estrelas. 2016 (6 min). Disponível em: https://www.youtube.com/watch?v=Wk7-IDzwmY4\&ab channel=LucAnderssen. Acesso em: 15 jan 2019.

BARTELMEBS, Roberta Chiesa.; MORAES, Roque. Astronomia nos anos iniciais: possibilidades e reflexões. Revista Espaço Pedagógico, Passo Fundo RS, v. 19, p. 341-352, Jul/Dez 2012. ISSN 2.

BRASIL. Base Nacional Comum Curricular. Ministério da Educação, 2018. Disponivel em: http://basenacionalcomum.mec.gov.br/wp-content/uploads/2018/02/bncc-20dez-site.pdf. Acesso em: 15 jan. 2019.

BOGDAN, Robert C.; BIKLEN, Sari Knopp. Investigação Qualitativa em Educação: uma introdução à teoria e aos métodos. Porto, Portugal. Porto Editora. 1994

BORGES, Elizandra Freitas. A literatura infantil no ensino da Astronomia: modelos mentais sobre Sistema Solar e estrelas de estudantes do $7^{\circ}$ ano do Ensino Fundamental. Dissertação - 
Programa de Pós-Graduação em Educação em Ciências e Matemática na Universidade Federal de Goiás. Goiânia, p. 213, 2018.

CANIATO, Rodolpho. O CÉU. 2a . ed. São Paulo : Ática S.A., 1993.

CARVALHO, Gabriel. Dias. Os campos conceituais de Vergnaud como ferramenta para o planejamento didático. Caderno Brasileiro de Ensino de Física. v. 25, n.2. p. 207-227. 2008.

LANGHI, Rodolfo. Aprendendo a ler o céu. 2a . ed. São Paulo: Livraria da Física, 2016.

LOUZADA, Alexandre Neves; ELIA, Marcos da Fonseca; SAMPAIO, Fábio Ferrentini. Concepções alternativas dos estudantes sobre conceitos térmicos: Um estudo de avaliação diagnóstica e formativa. Revista Brasileira de ensino de Física, v. 37, n. 1, 2015

MOREIRA, Marcos Antonio. A Teoria dos Campos Conceituais de Vergnaud, o ensino de Ciências e a pesquisa nesta área. Investigação em Ensino de Ciências. V. 7. P. 7-29. 2002.

PACHECO, Mayara Hilgert; ZANELLA, Marli Schmitt. Panorama de pesquisas em ensino de Astronomia nos anos iniciais: um olhar para teses e dissertações. Revista LatinoAmericana de Educação em Astronomia, n. 28, p. 113 - 132, 2019. Disponível em: https://www.relea.ufscar.br/index.php/relea/article/view/423. Acesso: 20 de agosto de 2020.

SCHEFFLER, Guilherme Luiz. A Teoria dos Campo Conceituais de Vergnaud e o ensino de Radioatividade. Trabalho de conclusão de curso para obtenção do grau de Licenciado em Química na Universidade Federal do Rio Grande do Sul, Porto Alegre 2011.

SIMON, Paula Cristina da Silva Gonçalves. Ensino de Astronomia Para os anos iniciais: uma proposta a partir da observação da Lua. Dissertação - Programa de Pós-Graduação Profissional em Educação, São Carlos , p. 210, 2016.

SOUSA, Célia Maria Sousa Gomes; FÁVERO, Maria Helena. Análise de uma situação de resolução de problemas e física em situação de interlocução entre um especialista e um novato, à luz da Teoria dos Campo Conceituais de Vergnaud. Investigação em Ensino de Ciências. V. 7. P. 55-75. 2002

VERGNAUD. Gerard La théorie des champs conceptuels, recherches em Didactique des Mathématiques, 10 (23), pp. 133-170, 1990.

VERGNAUD, Gerard. The Theory of Conceptual Fields. In: Human Development. Vol. 52, $\mathrm{n}^{\mathrm{o}}$ 2. Printed in Switzerland: Karger, p. 83-94, 2009. Acesso on line: 〈www.karger.com/hde〉.

ZABALA. Antoni. A prática educativa: como ensinar. Porto Alegre, RS. Ed. ARTMED. 1998.

\section{Agradecimentos}

Ao Grupo de Pesquisa em Ensino de Ciências e Matemática (GPECMA), no qual os estudos sobre a Teoria dos Campos Conceituais foram iniciados. 